\title{
Odour studies and health risk assessment: two complementary approaches in response to residents' complaints
}

\author{
G. Deiber, J. Boudaud \& L. Pourtier \\ EOG, France
}

\begin{abstract}
In this paper we present an approach to assess odour impact is based on odour measurements and air dispersion modelling. This approach makes it possible to estimate the frequency of odour perception and nuisance in the near vicinity of industrial, agricultural or municipal facilities.

A health risk assessment, based on toxicological reference values (TRVs), is also presented in order to consider the toxicity of odorous molecules in impact studies (chronic exposure of the population).

This paper reports the joint and complementary characteristics of these two approaches.
\end{abstract}

Keywords: odour, impact, health, risk, assessment, modelling, toxicity, olfactive, complaints, olfactometer.

\section{Introduction}

Concern over the toxicity of odours emitted by industrial sites are often put forward by local residents. In general, the population thinks that bad odours are toxic, which is not necessarily true. For example, hydrogen sulphide can be beneficial as a thermal cure but may be toxic if perceived between 10 and $250 \mathrm{ppm}$, and even deadly at concentrations beyond $500 \mathrm{ppm}$ (short exposure to concentrations between 500 and 1,500 ppm leads to respiratory paralysis and death) [1]. Carbon monoxide however is odourless but deadly beyond $800 \mathrm{ppm}$ [2].

In reply to these concerns, two approaches may be developed: first, the odour problem (type, source, impact of odours on resident populations and solutions to reduce olfactive emissions) and second, the toxicity aspect of these odorous 
molecules (hazard identification, quantification of exposure levels, risk assessment) [3]. The methods and problems covered by these two approaches, developed in four stages, are complementary and joint.

\section{Characterization of the site}

Standardized olfactometric measurements are required on the odorous sources when a facility has an impact on the air quality and causes citizen complaints. Odorous air samples are sent to an odour laboratory to determine the odour concentration of each of the odorous sources as well as the odour emission rate in order to establish their hierarchy and to determine their contribution to the overall odours at the site.

A physico-chemical diagnosis is conducted for all the on-site emissions in order to identify the principal molecules emitted into the atmosphere. The type, flow, data on toxicological effects on humans of each chemical compound determine the risk tracer compounds selected to assess the human health risks.

Furthermore, an environmental study of the site is carried out to identify its surrounding socio-economic context (other industries, census of populations and their residence area, rural or urban area, etc.).

\section{Hazards identification and dose-response ratio}

The ratio between the exposure level to odours and pollutants and the incidence and gravity of these effects is estimated. For odorous molecules, the main route of exposure is through inhalation.

In France, regulatory emission values have been issued concerning the odour output allowed, based on the height of the emissions for classified facilities for the protection of the environment (IPCE), "beyond which discomfort may be felt in the surrounding area" (Decree of February 2, 1998, Article 29 and its Application Circular of December 17, 1998). In particular, for the treatment of cadavers, wastes or by-products of animal origin (Decree of February 12, 2003), "the odour output must comply with the following air quality objectives: the odour concentration calculated within a radius of $3 \mathrm{~km}$ from the property limits of the site must not exceed $5 o u_{\mathrm{E}} / \mathrm{m}^{3}$ for more than 175 hours per year for an existing facility" [4]. These reference values for odour concentrations and the associated olfactive discomfort are based on both the source and the environment.

The French law on air (December 30, 1996) and its decrees (May 6, 1998 and February 15, 2002) recommends that "the air we breathe must not be harmful to our health" and defines the environmental values for chemical pollutants (air quality objectives).

Chemical substances of the odour may have acute effects (due to strong exposure for a short period) and sub-chronic or chronic effects (due to low exposure for a long period). We also differentiate pollutants with threshold effects (there is a level of exposure below which there is no risk) and pollutants without a threshold (any amount of exposure carries with it a degree of risk). 
For each selected pollutant, the intrinsic effects on human health, particularly through inhalation, is examined. The Toxicological Reference Values (TRVs) available in toxicological databases (WHO, US EPA, ATSDR, etc.), specific to each pollutant, serve as a reference for exposure limits for populations living around the facility. These TRVs, based on an epidemiological study or animal experiments, are established for a specific duration for a given route of exposure.

\section{Exposure assessment}

The assessment of the exposure of populations may be conducted for odours and for pollutants through an air dispersion modelling. This method allows a determination of foreseeable environmental concentrations of odours or pollutants, their area of impact and establishes the frequency in which the threshold value is exceeded. An example of this map is given in Figure 1 for exposure levels to a pollutant (fictitious case).

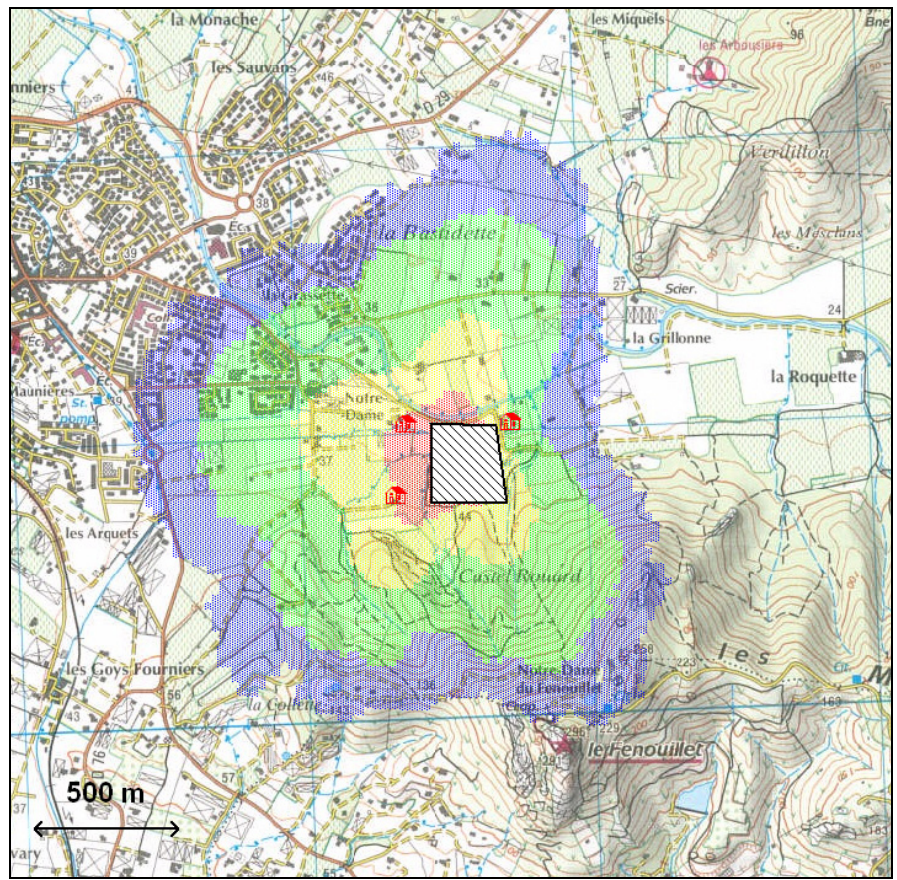

Figure 1: $\quad$ Example of a result from air dispersion modelling.

Furthermore, physico-chemical measurements may be conducted at different points in the environment in order to verify the consistency of results obtained by modelling or to quantify environmental concentrations if the modelling is not adapted. 
The impact of odours may also be quantified through the following methods:

- a citizen survey to obtain feedback on the olfactive perception of the residents, the discomfort caused by olfactive nuisances and the main areas affected by these odours;

- an olfactive observation campaign carried out by volunteers trained to recognize odours to provide a qualitative description of odours perceived and the impact differences.

\section{Risk characterization}

Within the context of odour studies, the odour output at emission and the frequency in which threshold values are exceeded in the environment are compared to the reference values. In addition, the calculation of olfactive comfort indices (stipulated in the French decree of February 12, 2003) allows the drawing up of maps (Figure 2) indicating the different areas with the associated comfort indices (good, average, degraded, poor).

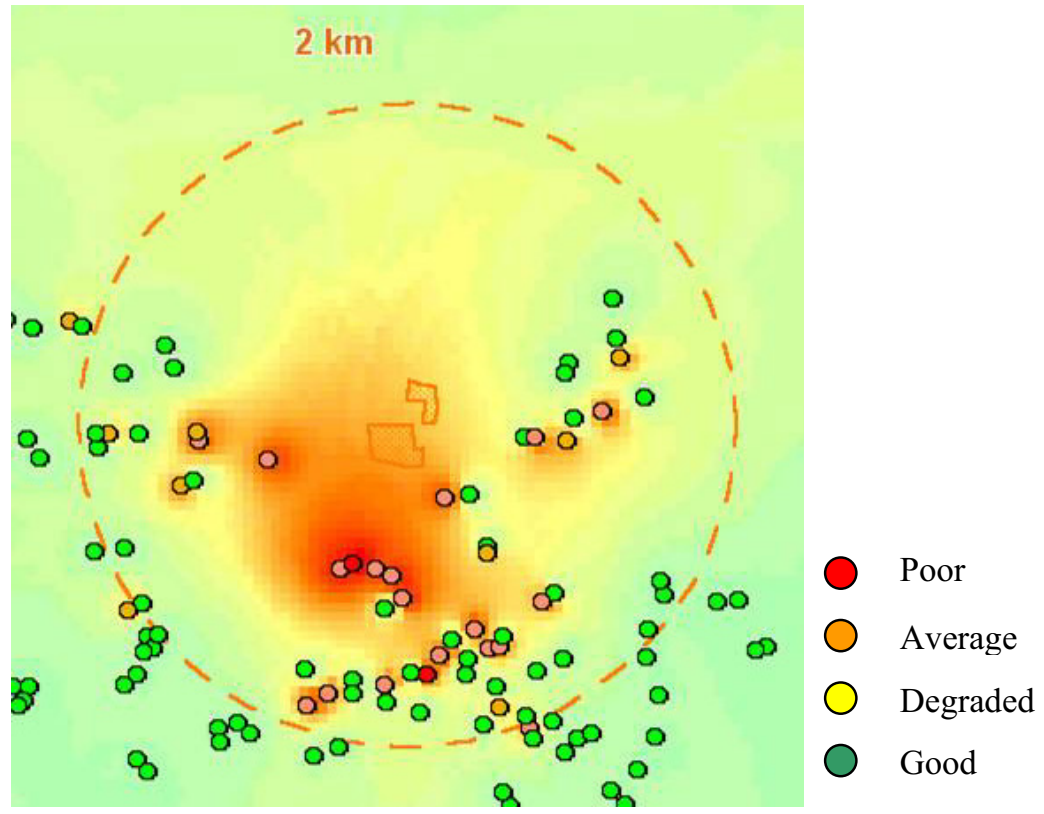

Figure 2: $\quad$ Comfort indices for populations living near a facility.

Within the context of the health risk assessments, environmental concentrations of pollutants are compared with the Toxicological Reference Values in order to establish if there is a health risk for the residents. 
Based on results obtained, it may be necessary to reduce emissions at the source both for the odours and pollutants.

The odour studies and health risk assessments are two problems which are:

- Complementary, insofar as they cover the olfactive perception, the discomfort aspect and the chemical risk,

- Joint, since odour is a perception resulting from the stimulation of the olfactive system through a more or less complex mixture of chemical molecules which may present different degrees of toxicity.

\section{References}

[1] EHC, Environmental Health Criteria $\mathrm{n}^{\circ}$ 19, Hydrogen sulphide, WHO, 1981. Online. http://www.inchem.org/documents/ehc/ehc/ehc019.htm

[2] EC (European Commission), Critical Appraisal of the Setting and Implementation of Indoor Exposure Limits in the EU, pp. 62, January 2005

[3] NRC (National Research Council), Committee on the Institutional Means for Assessment of Risks to Public Health, Risk Assessment in the Federal Government: managing the process, National Academy, Press Washington, 1983

[4] ADEME, Pollutions olfactives : Origine - Législation - Analyse Traitement, DUNOD: Paris, 2005 